\title{
Impact of Job Related Stress on Employee Performance: A Review and Research Agenda
}

\author{
R.G.Ratnawat ${ }^{1}$, Dr P.C. Jha ${ }^{2}$ \\ ${ }^{I}$ (Research Scholar,BIT,MESRA,Ranchi,India) \\ ${ }^{2}(B I T, M E S R A$, Ranchi,India $)$
}

\begin{abstract}
Impact of occupational stress on employee performance has been recognized as an important area of concern for organizations. Negative stress affects the physical and mental health of the employees that in turn affects their performance on job. Research into the relationship between stress and job performance has been neglected in the occupational stress literature (Jex, 1998). It is therefore significant to understand different Occupational Stress Inducers (OSI) on one hand and their impact on different aspects of job performance on the other. This article reviews the available literature to understand the phenomenon so as to develop appropriate stress management strategies to not only save the employees from variety of health problems but to improve their performance and the performance of the organization. 35 Occupational Stress Inducers (OSI) were identified through a comprehensive review of articles and reports published in the literature of management and allied disciplines between 1990 and 2014. A conceptual model is proposed towards the end to study the impact of stress on employee job performance. The possible data analysis techniques are also suggested providing direction for future research.
\end{abstract}

Keywords: Stress, Occupational Stress Inducers (OSI), Stressors, Impact, Performance

\section{Introduction}

Stress is many times misunderstood and misinterpreted resulting into avoidable problems. It is therefore important to understand the stress well before thinking of managing it.

The definition of stress has changed over the years. Initially it was considered as environmental pressure, then strain within the person. Stress is a psychological and physical state that results when the resources of the individual are not sufficient to cope with the demands and pressures of the situation. Thus, stress is more likely in some situations than others and in some individuals than others (Michi, 2002). Stress is defined as a response to a demand that is placed upon a person. It can be simply understood as "a condition where one experiences a gap between the present and desired state." Merriam Webster (1998) defined stress as a physical, chemical or emotional factor that causes bodily or mental tension and may be a factor in disease causation. It is a normal reaction when the brain recognizes a threat. When the threat is perceived, the human body releases hormones that activate its "fight or flight" response. Psychologist Richard S. Lazarus described stress as "a condition or feeling that a person experiences when s/he perceive that the demands exceed the personal and social resources the individual is able to mobilize." Beehr (1976) defined stress in very general terms as 'anything about an organizational role that produces adverse consequences for the individual'. For most people, stress is a negative experience. However Lazarus (1991) argued that, stress is a transaction, a dynamic process, that keeps on changing according to the role played by stress moderators with the changing external economic and financial environment in different societies. Hans Seyle (1956) cited in Sengupta (2007), one of the founding fathers of stress research, first introduced the term "stress" to describe physical and psychological responses to severe conditions or influences. He used the word "stress" which is an engineering term, to describe the responses to a force that when implemented in bodies, causes deformation. He further stated that stress is not necessarily something bad; it depends on how you take it. The stress of exhilarating, creative, successful work is beneficial while that of failure, humiliation or infection is detrimental. The stress can be classified into two types:

a) Eustress: Positive, pleasant or curative stress

b) Distress: Dysfunctional or negative stress

In the day to day life however, stress is considered to be negative only. For the sack of simplicity we will use only negative connotation of stress as that is more important from the subject point of view. Stress can be got over better if one knows the stressors or sources of stress.

Occupational stress is a significant and costly problem, and that the challenge for the organizations is to manage work stress in order to reduce health-care costs and improve productivity (Lawrence,1995). It may lead to increased health problems leading to higher rate of absenteeism and turn over, more accidents and poor job performance. While there is an agreement among researchers on the stress related terminology adopted 
(Maslach, 1998 cited in Ahmed \& Ramzan,2013), Cummings and Cooper (1998) pointed out the difficulty in developing a coherent theory on stress, as different research methodologies and disciplines (medicine, psychology, sociology, management) have looked into this area. Owing to this difficulty, not much quality research is available in this subject area. Beehr\&Newman (1978) attributed the lack of progress in the area of stress research to the fact that stress seemed to be related to a large number of conditions that prevented a systematic focus. Majority of available research and theories about job related stress have been developed and empirically tested in western context. However the problem of job related stress and its consequences is more important for developing countries as these are undergoing enormous social and economical changes (Jamal, 1999; Xie, 1996).

Occupational stress has become a challenge for the employer organizations as it results in low productivity, increased absenteeism and collection of other employee problems like alcoholism, drug abuse, hypertension and host of cardiovascular problems (Meneze,2005). Seibt et al., (2008) stated that stress is always present among employees however it can be reduced by improving the working conditions and quality of benefits in the companies

\section{Significance of Study}

The study can be significant particularly for two sets of stake holders namely the employers who after knowing the occupational stress inducers(OSI), can adopt appropriate strategies to reduce the occupational stress thereby enhancing the employees' job performance; and the employees who after being aware can take appropriate steps to reduce their own stress saving themselves from variety of health issues and also help management to implement the stress management strategies.

\section{Literature Review}

The focus of this article is to review the literature about the impact of stress on job performance. It is therefore imperative to briefly review the impact of stress on human body that in turn affects their job performance followed by review of literature on impact of stress on employees' job performance. The relevant review is presented hereunder.

\section{Impact of stress on human body:}

Sengupta (2007) stated that stress may cause physiological, behavioral or even psychological effects:

Physiological - hormone release triggers fight or flight response of humans. These hormones help them to either fight harder or run faster. They increase heart rate, blood pressure, and sweating. Stress has been tied to heart disease. Because of the increase in heart rate and blood pressure, prolonged stress increases the tension that is put on the arteries. It also affects the immune system which is why cold and flu illness usually show up during exams.

Behavioral - it may cause people to be jumpy, excitable, or even irritable. The effects of stress may cause some people to drink or smoke heavily, neglect exercise or proper nutrition, or overuse either the television or the computer.

Psychological - the response to stress may decrease the ability to work or interact effectively with other people, and be less able to make good decisions. Stress has also been known to play a part in anxiety and depression (Sengupat, 2007).

The structure of the Occupational Stress Indicator (OSI) demonstrates that stressful transactions are seen as a product of two intervening systems: people both exert an influence on and respond to their environments (Cooper, Sloan, \& Williams, 1988). In other words, the process of stress depends on a person's appraisal of a situation. Stress occurs when the magnitude of the stressor exceeds the individual's capacity to cope. As advocated by Lazarus (1991), a transactional, process, and appraisal approach is needed to study work stress.

\section{Impact of stress on job performance:}

Majority of the articles reviewed by this researcher mentioned about the impact of stress but many of them only talk about the impact of stress on particular aspect or dimensions of job, that means the researcher has not come across any article or report that takes a comprehensive view of the subject. Hence it is pertinent to understand as to what constitutes job performance or what are the different dimensions of job that are likely to be affected by stress. Scullen (2000) described job performance comprising of four aspects; i) general performance, ii) human performance, iii) technical performance and iv) administrative performance. Rubina et al. (2008) viewed job performance as the result of three factors working together: skill, effort and the nature of work conditions. Skills include knowledge, abilities and competencies of the employees; effort is the degree of motivation the employee puts forth towards completing the job; and the nature of work conditions is the degree of accommodation of these conditions in facilitating the employee's performance. 
The whole concern for the organizations is performance of their employees irrespective of factors and conditions. Good performance of employees leads to good organizational performance which is an indicator of their success (Armstrong \& Baron, 1998). Ultimate success or failure of an organization is determined majorly by the performance of their employees (Bartlett \& Ghoshal,1995 in Ahmed and Ramzan, 2013).

Stress has significant impact on company and people performance and it terribly affects health of employees (Mimura and Griffiths, 2003 in Shah et al, 2012). The studies conducted in western countries have shown that the sources of stress that we name as Occupational Stress Inducers (OSI) in this study are negatively related to well-being and job satisfaction of employees. (Robertson, Cooper, \& Williams, 1990). Shah et al. (2012) in their study on impact of stress on employee performance among teaching faculty, found a negative relationship between organizational structure and employee efficiency while rewards were found to be positively correlated to employee efficiency as expected. Rubina et al. (2008) too found a negative relationship between job stress and job performance. However the male employees were found to be affected more than their female counter parts. Munir and Islam (2011) tested relationship between work stressors like role ambiguity, workload pressure, home-work interface, performance pressure, relationship with others and role conflicts on one side and job performance on the other with motivation as mediator and found that 'role conflict' and 'role ambiguity' have a positive relation with stressors against the common notion while the relationship is found to be negative between other stressors and job performance. Imrab et al. (2013) found that stress is responsible for decreasing the performance of bank employees. Ahmed \& Ramzan (2013) too found a negative correlation between stress and job performance i.e as the stress increases the job performance goes down and vice-a-versa. Usman Ali et al. (2014) found that workload, role conflict, and inadequate monitory reward are the prime reasons of causing stress in employees that leads to reduced employee efficiency. Deshinger (2003) suggested that different aspects of employee job performance that are likely to be affected by stress include Productivity, Job Satisfaction / Morale, Absenteeism, Decision Making Abilities, Accuracy, Creativity, Attention to Personal Appearance, Organizational Skills, Courtesy Cooperation, Initiative , Reliability, Alertness , Perseverance and Tardiness.

The above described effects of stress (distress) affect the performance of humans and therefore it is important to understand how it can be managed well so as not only keep oneself happy and healthy but perform to best of the ability. Following figure 1(Sengupta, 2007) depicts the effect of stress on performance.

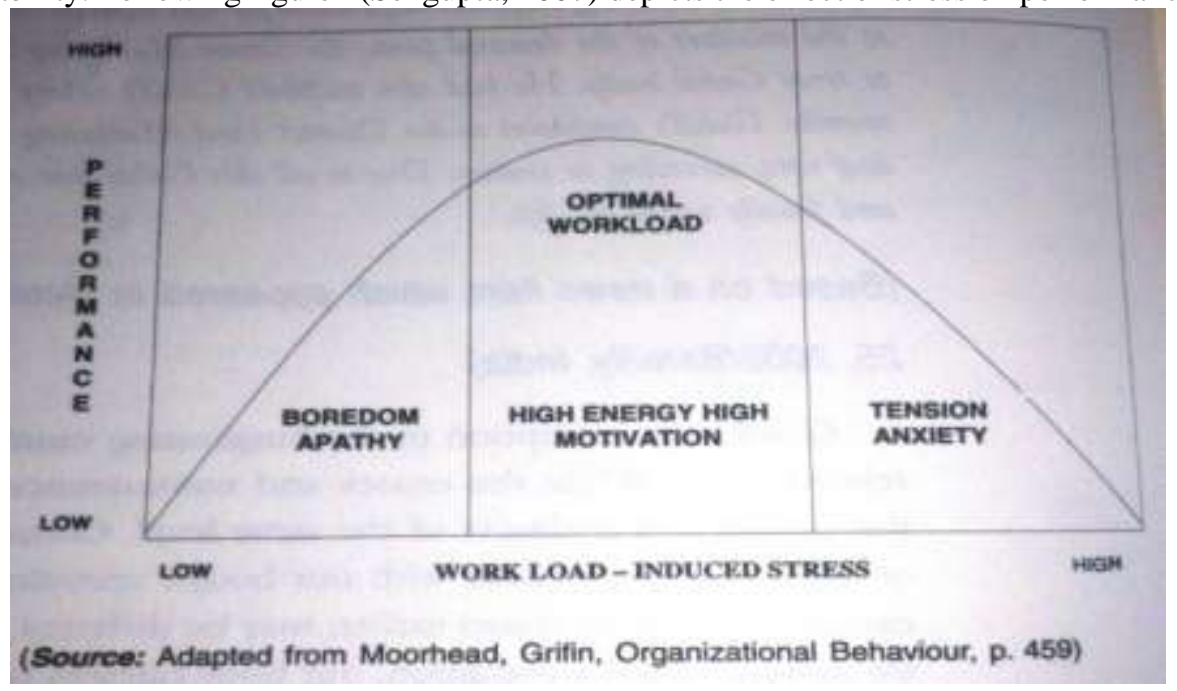

Figure 1: Work related stress and performance

\section{Methodology}

This review was performed by searching and reviewing the articles and reports published in different journals and books largely between 1990 and 2014 with exception of few articles published before 1990. The key words used in the search included stress, Stressors, Occupational Stressors, Factors of Stress, Job performance, Employee Performance etc. Manual search of bibliographies on related articles was also performed to identify the relevant literature. Scope of the studies reviewed in this article is limited to the impact of occupational stress (distress) on different aspects (dimensions) of job performance in work settings.

\section{Findings}

The major objective of this article is to identify the Occupational Stress Inducers (OSI) so that research can be conducted to study the impact of stress (represented by different OSI) and the employees' job performance. Then proposing a model to suggest the lines on which this study can be conducted is another 
major objective of this article. There are varying perspectives to sources of occupational stress. Evers, Frese, and Cooper (2000) found six items as valid OSI (occupational Stress Indicators) that measure stress; "intrinsic to the job," "organizational role," "relation- ships with others," "organizational structure and climate," "home/work interface," and "career and achievement." Card (2002) divided the stressors into six categories comprising of factors 'Intrinsic to job' , 'Role in the Organization', 'Career Development', 'Organizational climate', 'Relationships in the Organization' and 'Personality Factors'. Joy and Radhakrishnan (2013) put the stressors into four categories of 'work related', 'organization related', 'relationships at work' and 'career development'. They further found that for male factory workers the financial problems / low wages followed by poor physical environment, Dual career, Threat to job security, Social / Physical isolation, Personal / family problem, No role in decision making, Boring repetitive work, Frustration over career ambition ,and Harassment and bullying were found to be significant stressors in decreasing order of importance while for female workers the stressors were in terms of Dual career, Financial problems / low wages, Personal / family problems, Social / physical isolation, Poor physical environment, Frustration over career ambition , Boring repetitive work, Threat to job security, No role in decision making , and Harassment and bullying in the decreasing order of intensity. Other authors have dealt with individual factors largely falling into one or the other categories cited above. 35 variables identified through this review in terms of OSI have been put into six categories as shown in table 1. An additional category of miscellaneous factors has been added in the proposed model to take care of missing factors if any.

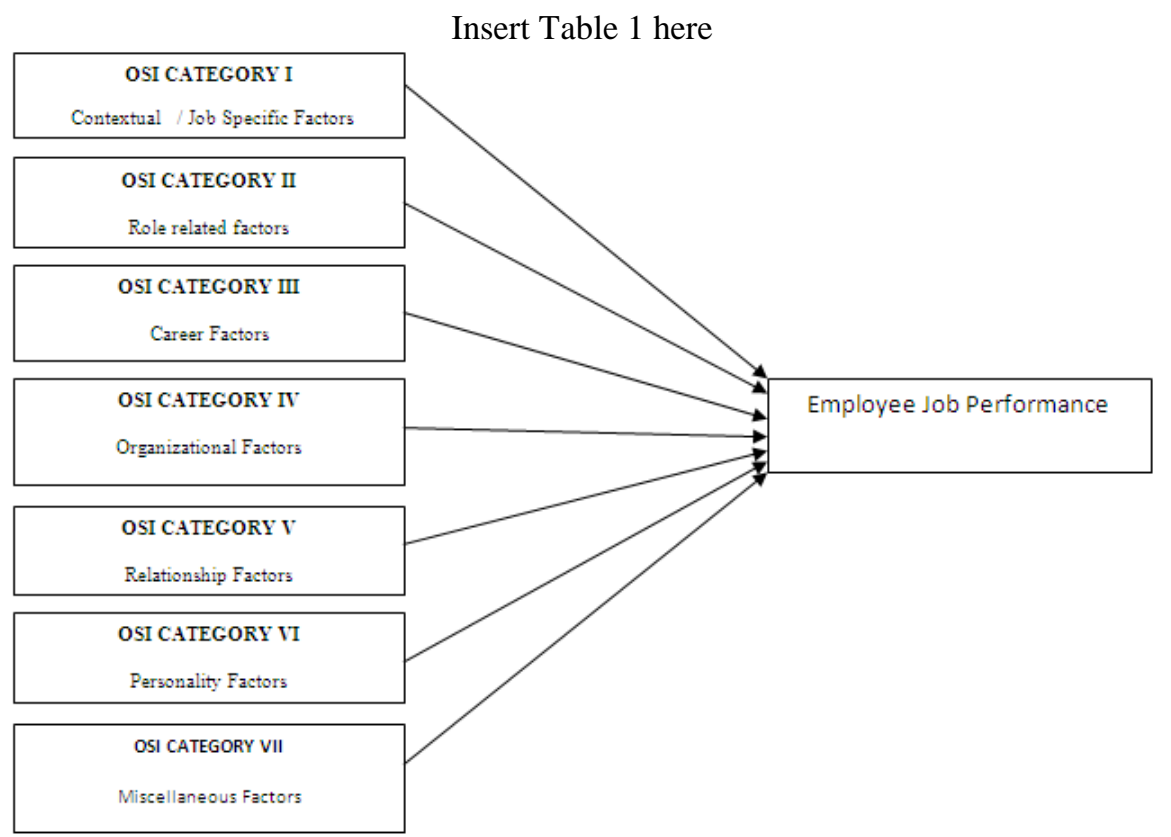

Figure 2: Proposed Model to Study Impact of Stress on Job Performance

\section{Proposed Model}

The researcher proposes the model as shown in figure 2 to study the relationship between the stress represented by OSI as given in table 1 on one side and the job performance of employees on the other. The factors of job likely to be affected may vary with the jobs. Dishinger et al (2003) suggested that the factors likely to be affected by stress range from productivity to competencies to inter personal behavior as mentioned above. Though the employee performance is shown in the figure as a single factor, it can be considered to be made up of multiple factors or dimensions of job. Accordingly the model can be modified. In case multiple job dimensions are considered for study, these should be chosen based on their importance and relevance after due validation. A questionnaire survey can be conducted by taking the above 35 variables and missing variables if any, to identify the most relevant and important factors which may be bundles of OSI. These factors can be determined with the help of Exploratory Factor Analysis (EFA) followed by multiple regression. Alternatively Confirmatory Factor Analysis (CFA) can directly be applied to identify the most relevant OSI and their impact on job performance as the stressors are already identified based on the available theory. 


\section{References}

[1]. Agrawal, Rita (2001) Stress in Life and at Work, Response Books, New Delhi, $1^{\text {st }}$ edition

[2]. Ahmed \& Ramzan (2013) Effects of Job Stress on Employees Job Performance :A Study on Banking Sector of Pakistan, IOSR Journal of Business and Management, Vol. 11, Issue 6 pp 61-68.

[3]. Armstrong, M.\& Baron,A.(2007) Performance management: A strategic and integrated approach to achieve success, , 3rd ed. Jaico Publishing House, Mumbai

[4]. Badra-Ul Islam and Munir Kashif (2011) Impact of Stressors on the performance of employees, Munich Personal RePEc Archive

[5]. Bartlett \& Ghoshal (1995) in Ahmed \& Ramzan (2013) Effects of Job Stress on Employees Job Performance :A Study on Banking Sector of Pakistan, IOSR Journal of Business and Management, Vol. 11, Issue 6 pp 61-68.

[6]. Beehr, T.A.(1976). Perceived situational moderators of the relationship between subjective role ambiguity and role strain. Journal of Applied Psychology;61:35-40.

[7]. Beehr,T.A.\& Newman, J.(1978) Job stress, employee health and organizational effectiveness: A facet analysis, model, and literature review. Personal Psychology, 31:665-9

[8]. Calpoly, undated (Undated ) Stress Management, Academic Skills Center California Polytechnic State University San Luis Obispo, California, http://sas.calpoly.edu/asc/ssl.html

[9]. Card, H.L.(2002) Effective Stress Management :A Personal Guide, An Occupational Psychology Division ,USA

[10]. Charles Dishinger, Nancy Howard, Bill Kiagler, Sherry Seabrooke and Donna Tucker (2003) The Effects of Stress on Business Employees and Programs Offered by Employers to Manage Stress, Southwest Texas State University

[11]. Cummings and Cooper (1998) in Ahmed \& Ramzan (2013) Effects of Job Stress on Employees Job Performance A Study on Banking Sector of Pakistan, IOSR Journal of Business and Management, Vol. 11, Issue 6 pp 61-68.

[12]. Darton, K.(2012) How to Manage Stress, MIND: National Association for Mental Health, London

[13]. Evers, A., Frese, M., \& Cooper, C. L. (2000). Revisions and further developments of the Occupational Stress Indicator: LISREL results from our four Dutch studies, Journal of Occupational and Organizational Psychology, 73, 221-240.

[14]. Jamal, M. (1999). Job stress, Type-A behavior, and well-being: A cross-cultural examination, International Journal of Stress Management, 6, 57-67.

[15]. Jex, S. M. (1998). Stress and Job performance. Thousand Oaks, CA: Sage.

[16]. Joy,J. and Radhakrishnan, D.(2013) A Study on Causes of Work Stress among Tile Factory Workers in Kannur District in Kerala, International Journal of Scientific and Research Publications, Volume 3, Issue 9, September 2013

[17]. Klinic Community Centre (2010) Stress and Stress Management, Winnipeg MB , Canada

[18]. Lawrence R. Murphy, (1995) Managing job stress: An employee assistance/human resource management partnership, Personnel Review, Vol. 24 Iss: 1 , pp.41-50

[19]. Lazarus, R. S. (1991). 'Psychological stress in the workplace' in P. L. Perrewé (Ed.), Handbook of job stress [Special Issue]. Journal of Social Behavior and Personality, 6, 1-13.

[20]. Levey, R.E.(2001) Sources of stress for residents and recommendations for programs to assist them . Acad Med;76:142-50

[21]. Manzoor, A. , Awan, H. and Mariam, S.(2011) Investigating the Impact of Work Stress on Job Performance: A Study on Textile Sector of Faisalabad, Asian Journal of Business and Management Sciences, Vol 2, No.1,p 20-28

[22]. Maslach(1998) in Ahmed \& Ramzan (2013) Effects of Job Stress on Employees Job Performance A Study on Banking Sector of Pakistan, IOSR Journal of Business and Management, Vol. 11, Issue 6 pp 61-68.

[23]. Meneze, M.M. (2005). The Impact of Stress on Productivity at Education Training \& Development Practices: Sector Education and Training Authority

[24]. Michie S. (2002) Causes and management of stress at work. Occupational and Environmental Medicine;59: 67-72

[25]. Michie, S. and Williams, S. (2003) Reducing psychological ill health and associated sickness absence: A systematic literature review, Occupational and Environmental Medicine, Volume 60, Pages 3-9

[26]. Mimura, C. and Griffiths (2003) The effectiveness of current approaches to workplace stress management in the nursing profession: An evidence based literature review. J. Occup. Environ. Med., 60: 10-15 in Shah et al (2012) Impact of Stress on Employee's Performance: A Study on Teachers of Private Colleges of Rawalpindi, Asian Journal of Business Management,4(2),101-104.

[27]. Morimoto,H.(2006) The present situation of personal assistant staff's mental health in medical welfare and ways to maintain their mental health by work stress study ,Kawasaki Medical Welfare Journal,16(31-40),

[28]. Oi-ling Siu(2003) Job stress and job performance among employees in Hong Kong: The role of Chinese work values and organizational commitment ,International Journal of Psychology,38(6),337-347

[29]. Rubina Kazmi, Shehla Amjad, Delawar Khan(2008) Occupational stress and its effect on job performance a case study of medical house officers of district Abbottabad, J Ayub Med Coll Abbottabad,20(3)

[30]. Seibt, et al(2008) Predictors of work ability in occupations with psychological stress. Journal of Public Health, 17: 9-18

[31]. Sengupta, D.(2007) You Can Beat Your Stress, Excel Books, New delhi, $1^{\text {st }}$ edition

[32]. Shaheen Imrab, Mrs. Batool Qudsia, Dr. Sajid Mushtaq A., Mr. Nabi Ghulam (2013) Impact of stress on the performance of employees of banks in Kotli , International Journals of Marketing and Technology, Vol 3, Issue 6,p 85-98

[33]. STOICA ,M. \& BUICU,F.(2010) Occupational Stress Management, Human Resource Management, XIV/2 / pp 7-9

[34]. Xie, J. L. (1996). Karasek's model in the People's Republic of China: Effects of job demands, control, and individual differences. Academy of Management Journal, 39, 1594-1618.

Table 1: Occupational Stress Inducers(OSI)

\begin{tabular}{|l|l|l|}
\hline S NO & Name of OSI & Authors / Researchers \\
\hline OSI Category I & Intrinsic to job / Contextual factors & $\begin{array}{l}\text { Card, H.L.(2002): Evers, Frese, and Cooper (2000); } \\
\text { Morimoto(2006); Imrab et al(2013) }\end{array}$ \\
\hline 1 & Too much work / Work load Pressure & $\begin{array}{l}\text { Card, H.L.(2002); Islam and Munir (2011) } \\
\text { Usman Ali et al (2014);Manzoor, } \\
\text { Awan\&Mariam(2011) }\end{array}$ \\
\hline 2 & & Card, H.L.(2002) \\
\hline 3 & Too less work & Card, H.L.(2002) \\
\hline 4 & Time pressures / Deadlines & Card, H.L.(2002); Manzoor,Awan \& Mariam(2002) \\
\hline 5 & Poor working conditions / Physical agents & Card, H.L.(2002) \\
\hline 6 & Mistakes & Manzoor,Awan \& Mariam(2011) \\
\hline 7 & Too many decisions & \\
\hline
\end{tabular}


Impact of Job Related Stress on Employee Performance: A Review and Research Agenda

\begin{tabular}{|c|c|c|}
\hline 8 & Reward structure & Shah et al (2012) \\
\hline 9 & Performance pressure & Islam and Munir (2011) \\
\hline OSI Category II & Role in the Organizations & $\begin{array}{l}\text { Card, H.L.(2002): Evers, Frese, and Cooper (2000); } \\
\text { Rubina(2008); Morimoto(2006); Islam and } \\
\text { Munir(2011); Imrab et al(2013) }\end{array}$ \\
\hline 10 & Role ambiguity / Lack of Role clarity & Card, H.L.(2002); Manzoor,Awan \& Mariam( ) \\
\hline 11 & Role conflict & $\begin{array}{l}\text { Card, H.L.(2002); Islam and Munir (2011) } \\
\text {; Usman Ali et al (2014) }\end{array}$ \\
\hline 12 & Too little responsibility & Card, H.L.(2002) \\
\hline 13 & No / less / lack of participation in decision making & $\begin{array}{l}\text { Card, H.L.(2002); Meneze (2005); Manzoor,Awan \& } \\
\text { Mariam (2011) }\end{array}$ \\
\hline 14 & $\begin{array}{l}\text { Lack of managerial support / Administrative support } \\
\text { / support at work }\end{array}$ & $\begin{array}{l}\text { Card, H.L.(2002); Shah et al (2012); Manzoor,Awan } \\
\text { \& Mariam (2011) }\end{array}$ \\
\hline 15 & Job insecurity / Job instability & Card, H.L.(2002); Manzoor,Awan \& Mariam( ) \\
\hline OSI Category III & Career Factors & Card, H.L.(2002); Evers, Frese, and Cooper (2000) \\
\hline 16 & Under promotion & Card, H.L.(2002) \\
\hline 17 & Fear of retirement & Card, H.L.(2002) \\
\hline 18 & Thwarted ambition & Card, H.L.(2002) \\
\hline 19 & Sense of being trapped & Card, H.L.(2002) \\
\hline 20 & Over promotion & Card, H.L.(2002) \\
\hline OSI Category IV & Organizational climate & $\begin{array}{l}\text { Card, H.L.(2002); Evers, Frese, and Cooper } \\
\text { (2000):Shah et al (2012) }\end{array}$ \\
\hline 21 & Organizational structure & Shah et al (2012); Usman Ali et al (2014) \\
\hline 22 & Lack of communication & Card, H.L.(2002); Rubina(2008) \\
\hline 23 & Restrictions on behavior & Card, H.L.(2002) \\
\hline 24 & Uncertainty & Card, H.L.(2002) \\
\hline 25 & Office politics & Card, H.L.(2002) \\
\hline 26 & Loss of identity & Card, H.L.(2002) \\
\hline 27 & Lack of sense of belonging & Card, H.L.(2002) \\
\hline OSI Category V & Relationships in organization & $\begin{array}{l}\text { Card, H.L.(2002); Evers, Frese, and Cooper (2000) } \\
\text {;Morimoto(2006); } \\
\text { (2011) }\end{array}$ \\
\hline 28 & Poor relations with boss & Card, H.L.(2002); Rubina(2008) \\
\hline 29 & Poor relations with colleagues & Card, H.L.(2002) \\
\hline 30 & Personality conflict & Card, H.L.(2002) \\
\hline 31 & Delegation difficulty & Card, H.L.(2002) \\
\hline OSI Category VI & Intrinsic to individuals / Personality factors & Card, H.L.(2002); Imrab et al(2013); \\
\hline 32 & Inability to cope with change & Card, H.L.(2002) \\
\hline 33 & Interpersonal problems & Card, H.L.(2002) \\
\hline 34 & Lack of insight into own stressors & Card, H.L.(2002) \\
\hline 35 & Fear of moving of our expertise & Card, H.L.(2002) \\
\hline OSI Category VII & Miscellaneous factors(if any) & \\
\hline
\end{tabular}

